\title{
Ultrasonography for biliary atresia and infantile hepatitis syndrome
}

\author{
Viroj Wiwanitkit
}

Accepted: 8 March 2011/Published online: 25 March 2011

(C) Springer-Verlag 2011

Editor, I read the recent publication on ultrasonography for biliary atresia (BA) and infantile hepatitis syndrome with a great interest [1]. Sun et al. [1] concluded that "The ultrasonographic features useful in the differential diagnosis of obstructive jaundice cases are measurement of the gallbladder size, observation of its form, investigations of the triangular cord (TC), and the presence of biliary lake in the area of the hepatic portal system." Indeed, there are some related publications on this area. Sun et al. concluded from a comparative study of two conditions. However, there are many other similar conditions to be concerned such as [2]. In a recent publication, Park et al. [2] noted that "BA cannot be ruled out when negative TC is coupled with an abnormal gallbladder, requiring further diagnostic modalities such as liver needle biopsy or hepatobiliary scintigraphy."

\section{References}

1. Sun Y, Zheng S, Qian Q (2011) Ultrasonographic evaluation in the differential diagnosis of biliary atresia and infantile hepatitis syndrome. Pediatr Surg Int (epub ahead of print)

2. Park WH, Choi SO, Lee HJ (1999) The ultrasonographic 'triangular cord' coupled with gallbladder images in the diagnostic prediction of biliary atresia from infantile intrahepatic cholestasis. J Pediatr Surg 34(11):1706-1710
V. Wiwanitkit $(\bowtie)$

WiwanitkitHouse, Bangkhae, Bangkok 10160, Thailand

e-mail: wiroj@yahoo.com 